\title{
Obrigatoriedade de matrícula na pré-escola: análise do ponto de vista das famílias
}

\author{
Aliandra Cristina Mesomo Lira \\ Universidade Estadual do Centro-Oeste/UNICENTRO \\ Leandra Souza Machado \\ Universidade Estadual do Centro-Oeste/UNICENTRO
}

\section{Resumo}

0 artigo tem como objetivo problematizar a obrigatoriedade de matrícula na préescola para crianças de 4 e 5 anos de idade, proposta pela Lei 12.796, e compreender qual a percepção dos pais com relação aos encaminhamentos envoltos no cumprimento da lei. A pesquisa é de cunho qualitativo, partindo de referencial teórico e análise documental e entrevistas com os responsáveis pelas crianças matriculadas na préescola. Foi possivel reconhecer que a obrigatoriedade não necessariamente significa uma pré-escola de qualidade e que os responsáveis interpretam a implementação da lei como direito 'de aprender' mais cedo, a despeito das condições de atendimento.

Palavras-chave: Obrigatoriedade. Educação Infantil. Família.

\section{Compulsory registration in kindergartens: analysis from the families' point of view}

\begin{abstract}
Compulsory registration in kindergartens for 4-5-year old children, imposed by Law 12.796, is problematized. The paper analyzes parents' perception with regard to procedures to comply with the law. Qualitative research comprises a theoretical reference, documental analysis and interviews with parents or tutors of children registered in the kindergarten. Compulsory registration does not necessarily warrant a quality education. Parents interpret the law as children's right to learn earlier in spite of attendance conditions.
\end{abstract}

Keywords: Duty. Children's education. Family. 


\section{Obligación de matrícula en la fase preescolar: análisis del punto de vista de las familias}

\section{Resumen}

Este artículo tiene como objetivo problematizar la obligación de la matrícula en la fase preescolar de los niños de 4 y 5 años de edad, propuesta por la Ley 12.796, y busca comprender cuál es la percepción de los padres en relación a la conducción para cumplir la ley. La investigación es de tipo cualitativo, partiendo de referencias teóricas y análisis documental, además de entrevistas con los padres o responsables por los niños matriculados en la etapa preescolar. Fue posible reconocer que la obligación no siempre significa encontrar una escuela de calidad, y que los padres o responsables interpretan la implementación de la ley como derecho 'de aprender' más temprano, respecto a las condiciones de atendimiento.

Palabras-clave: Obligación. Educación Infantil. Familia.

\section{Obligation d'enregistrement prescolaire : analyse du point de vue des familles}

\section{Resumé}

Cet article a l'objective de problématiser l'obligation d'enregistrement prescolaire d'enfants à l'âge de 4 et 5 ans selon la Loi 12.796 et comprendre la perception des parents concernant les directions pour obéir cette loi. Cette recherche est qualitative de référentiel théorique, d'analyse documentaire et interview avec les responsables par les enfants prescolaires enregistrés. Cela a été possible voir que l'obligation d'enregistrement ne garantit pas necessairement la qualité de l'école et que les responsables une qu'ils pensent que c'est un droigt 'apprendre' plus tôt malgré les conditions de service.

Mots-clé: Obligation. Éducation des Enfants. Famille.

\section{Introdução}

A obrigatoriedade de matrícula para crianças de 4 e 5 anos de idade foi prevista pela Emenda Constitucional (EC) n. 59 e reafirmada pela Lei n. 12.796 (Brasil, 2013a). Considerando o encaminhamento legal e as variadas questões envolvidas na implementação da obrigatoriedade, interessou-nos saber qual a percepção das famílias a respeito da necessidade de matricular seus filhos na pré-escola, buscando reconhecer 
pontos positivos e/ou dificuldades decorrentes do cumprimento dessa exigência legal.

Desse modo, como principal pergunta elegemos: Quais as expectativas e dificuldades enfrentadas pelas famílias com relação à extensão da obrigatoriedade do ensino? Dessa pergunta derivam outras, não menos importantes: sob o ponto de vista das famílias, a obrigatoriedade do ingresso na pré-escola é vista como um direito ou uma imposição? Os pais e responsáveis estão satisfeitos com essa condição? Quais benefícios elencam? Quais problemas estão enfrentando? A entrada obrigatória antecipada das crianças na escolarização formal interferiu na vida das famílias? Como? E das crianças? Para os pais, qual o papel da pré-escola?

O objetivo principal foi reconhecer, do ponto de vista das famílias, as expectativas e dificuldades decorrentes da obrigatoriedade de matrícula na pré-escola de crianças de 4 e 5 anos de idade e, além disso, identificar os ganhos e/ou problemas enfrentados pelas famílias e crianças no cumprimento da legislação, refletir acerca dos impactos da obrigatoriedade na vida social e familiar das crianças, problematizar a obrigatoriedade em contraponto com a liberdade de escolha das famílias, bem como compreender quais as expectativas familiares quanto ao papel da pré-escola para o desenvolvimento das crianças.

Abordamos o referido tema por meio de uma pesquisa caracterizada por uma abordagem de cunho qualitativo, assentada em reflexões a partir de autores da área da educação infantil e de políticas educacionais. Partiu-se da análise da legislação educacional, com posterior coleta de dados por meio entrevistas semiestruturadas com responsáveis (mães) ${ }^{1}$ por crianças que frequentam a educação infantil em duas instituições públicas de um município de médio porte no interior do Paraná.

O texto inicia dando ênfase às finalidades e aos objetivos da educação infantil, com destaque para o disposto na Lei de Diretrizes e Bases (LDBEN) n. 9394 (Brasil, 1996) e nas diretrizes Curriculares Nacionais para a Educação Infantil (DCNEI) (Brasil, 2009a). Em seguida, dedica-se mais especificamente ao tema da obrigatoriedade, a partir da EC n. 59 (Brasil, 2009b) e da Lei n. 12.796 (Brasil, 2013a). Em seguida, a partir das categorias de análise, são apresentados e discutidos os dados coletados com as mães das crianças que frequentam a pré-escola.

\section{Dos objetivos e finalidades da educação infantil}

O reconhecimento, nos termos da lei, de que a educação infantil passou a ser um direito das crianças, deu-se a partir da Constituição Federal de 1988 (Brasil, 1988), sendo proclamada como primeira etapa da educação básica pela LDBEN n. 9394

$1 \quad$ As participantes dessa pesquisa, por serem todas mães, explicitam as questões de gênero vivenciadas em nossa sociedade, onde as responsabilidades diretas pelos filhos recaem sobre as mulheres. 
(Brasil, 1996), que por meio de seu art. 29, diz: “A educação infantil, primeira etapa da educação básica, tem por objetivo o desenvolvimento integral da criança, em seus aspectos físico, psicológico, intelectual e social, complementando a ação da família e da comunidade". A LDBEN, porém não tornava essa etapa da educação obrigatória, pois o ensino era indicado como dever do Estado e a matrícula era facultativa aos pais de crianças com idade entre 0 e 5 anos.

Em 2009, a EC n. 59 previu a obrigatoriedade de matrícula em pré-escola para as crianças a partir dos 4 anos de idade, condição que foi referendada pela Lei n. 12.796 (Brasil, 2013a), ao estender a obrigatoriedade do ensino para as crianças de 4 e 5 anos, ou seja, para uma parte da educação infantil.

De modo geral, é possível observar um conjunto de conquistas relativamente recentes na área da educação infantil, inclusive no que diz respeito às práticas. De acordo com o Oliveira (1994), o currículo torna-se importante nos processos interativos para a constituição humana e seus contextos sociais e culturais. Embora em tratando-se de currículo o maior enfoque esteja nas ações pedagógicas, as tarefas que envolvem o cuidado e a educação para com as crianças precisam acontecer de modo articulado e integrado.

Nas práticas pedagógicas da educação infantil, o binômio cuidar e educar ganha relevância no sentido da integração das ações no trabalho com as crianças, uma vez que são compreendidos como ações indissociáveis e complementares.

Além disso, o currículo deve ser flexível no sentido de abarcar a diversidade que caracteriza nosso país, suas diferentes culturas e indivíduos. Isso significa considerar as subjetividades, as diferenças culturais, regionais e socioeconômicas que também se explicitam nas instituições de educação infantil (Brasil, 2009a).

Nesse sentido, a parceria entre as instituições e as famílias adquire relevância para o desenvolvimento da criança de forma integral. O caráter colaborativo e de complementação ganham importância, uma vez que a criança passa, em muitos casos, grande parte do dia nas instituições, que desenvolvem um trabalho que deve ser conhecido e compartilhado com os pais ou responsáveis. Segundo as DCNEl (Brasil, 2009a, p. 19), espera-se:

A participação, o diálogo e a escuta cotidiana das famílias, o respeito e a valorização de suas formas de organização;

O estabelecimento de uma relação efetiva com a comunidade local e de mecanismos que garantam a gestão democrática e a consideração dos saberes da comunidade [...].

Quanto à jornada de atendimento, as DCNEI (Brasil, 2009a) indicam que as crianças têm o direito de frequentar o período integral (de 7 horas ou mais) ou parcial ( 4 horas), a depender do interesse da família. Percebemos que, na prática, muitas vezes esse direito é negado, pois não há escolha por parte das famílias no que diz respeito ao 
horário em que a criança irá frequentar a instituição de educação infantil. Em alguns casos, torna-se obrigatório frequentar o período integral; em outros, como no caso do município pesquisado, para a pré-escola só é ofertada a jornada parcial.

Com relação ao trabalho com as crianças e a construção da identidade, as interações precisam ser estimuladas por meio de ricas experiências que envolvem as próprias crianças, seus pares e os adultos que com elas convivem. Nesse entendimento, reconhecese que as interações e brincadeiras entre as crianças são formas de comunicação, e por meio delas, há expressão de sentimentos e de vivências, internalização de regras e construção de valores, inclusive culturais e sociais. Assim, o brincar é de extrema importância para o desenvolvimento infantil, uma vez que o faz de conta muitas vezes contempla situações da realidade vivenciadas pelas crianças e por elas reinterpretadas.

Para tanto, faz-se necessário que os espaços e ambientes organizados para e com as crianças sejam seguros e ao mesmo tempo desafiadores, com rotinas flexíveis, onde as crianças possam acomodar seus jogos e brincadeiras, ouvir música, cantar, dançar, expressar-se por meio de desenhos, pintura, modelagem, dramatizações e colagem, dentre outras possibilidades.

Além da adequação dos espaços e ambientes internos e externos, a adequação do mobiliário é indicada com estantes acessíveis, mesas e cadeiras leves, vasos sanitários e pias na altura das crianças, assim como quadros e painéis (Brasil, 2006). A participação das crianças é, comumente, acionada pelo espaço em sua dimensão afetiva e subjetiva, mas a atenção às questões físicas é importante, pois contribui para um envolvimento mais significativo, mobilizando seus sentidos e proporcionando a ampliação de suas experiências.

Como forma de contribuir com os processos expressivos, as diferentes linguagens infantis devem ser incentivadas, estimuladas e trabalhadas com as crianças, dando lugar à curiosidade, ao questionamento, à exploração e ao conhecimento em relação ao mundo físico e social, por meio da interação e da expressão. Para que isso ocorra, é necessário que a criança seja vista como sujeito histórico e de direitos e que, ao mesmo tempo em que se apropria, vivencia e reproduz o mundo a sua volta, reinterpreta e produz cultura infantil.

Para tal, o profissional da educação infantil assume a importante tarefa de proporcionar condições para ampliação das experiências, promovendo na educação infantil o acesso a conhecimentos da esfera da cotidianidade da criança, respeitando os pequenos enquanto sujeitos em desenvolvimento. Desse modo, o professor tem a função de ser o mediador entre os conhecimentos científicos e os conhecimentos cotidianos trazidos pelas crianças, tendo sensibilidade e afetividade para fortalecer a autoestima, melhorar a autoconfiança, respeitando-as.

O direito à educação inclui também a exigência de qualidade e o respeito às necessidades da criança em cada fase do seu desenvolvimento: o direito à brincadeira, à atenção individual, ao aconchego e ao afeto, ao desenvolvimento da sociabilidade, assim como o direito à 
Assim, para atuar como profissional na educação infantil, a legislação exige formação específica (Brasil, 1996), mas infelizmente, apesar da importância dos professores para o desenvolvimento das crianças, muitas vezes não são reconhecidos pela sociedade como profissionais da educação. Como destacam Lira, Drewinski e Sapelli (2016, p. 90):

A precarização do trabalho docente se agrava com a desvalorização e desprestígio associados à figura do professor da educação infantil, o que engendra uma situação de insatisfação por grande parte dos profissionais que atuam na área. É comum encontrarmos em planos de carreira do magistério uma diferenciação de salários, entre os professores que atuam em turmas de educação infantil e dos anos iniciais.

Nesse contexto, os profissionais da educação infantil são comparados, ou até mesmo confundidos, com cuidadores, babás, ou qualquer outra denominação que não a de professor. Em muitas instituições de educação infantil, os professores são chamados de "tios" e "tias", o que é justificado para destacar o papel afetuoso que também exercem, mas por outro lado pode descaracterizar sua função educativa. Sobre essa questão, Freire (1997, p. 9) esclarece:

Isto não significa, porém, que a tarefa de ensinar transforme a professora em tia de seus alunos da mesma forma como uma tia qualquer não se converte em professora de seus sobrinhos só por ser tia deles. Ensinar é profissão que envolve certa tarefa, certa militância, certa especificidade no seu cumprimento enquanto ser tia é viver uma relação de parentesco. Ser professora implica assumir uma profissão enquanto não se é tia por profissão.

Dado o importante papel que exerce o professor da educação infantil, este precisa ser reconhecido como um profissional, que deve ser qualificado com formação inicial e continuada.

A partir do exposto, é possível reconhecer que, nos termos da lei, temos proposições bastante interessantes que buscam garantir o direito de todas as crianças a uma educação infantil de qualidade, contudo a efetivação de tais preceitos por meio das práticas pedagógicas e da gestão das instituições encontra dificuldades, tanto de ordem política como estrutural e profissional.

\section{A obrigatoriedade nos dispositivos legais}

Em 2009, a EC n. 59 previu a obrigatoriedade de matrícula em pré-escola para as crianças a partir dos 4 anos de idade, por meio de seu Art. 208, que enuncia: "Educação básica obrigatória e gratuita dos 4 (quatro) aos 17 (dezessete) anos de idade, assegurada inclusive sua oferta gratuita para todos os que a ela não tiveram acesso na idade própria" (Brasil, 2009b). Tal medida buscou ampliar o direito de todos à educação pública e gratuita, tornando o ensino básico e obrigatório no país um dos mais longos, em comparação com outros países. Segundo Cury (2008, p. 294), essa obrigatoriedade se deve ao fato de que a educação também é um princípio de cidadania: 
Esse papel o é como tal porque à educação the é imanente o de ser em si um pilar da cidadania e o é inda mais por ter sido destinado à educação básica o condão de reunir as três etapas que a constituem: a educação infantil, o ensino fundamental e o ensino médio. A educação básica é um conceito mais do que inovador para um país que, por séculos, negou, de modo elitista e seletivo, a seus cidadãos, o direito ao conhecimento pela ação sistemática da organização escolar.

A educação infantil representa a primeira etapa da educação básica e direito de todo cidadão. Contudo, há um grande hiato entre a proclamação do direito e sua efetivação, pois há algum tempo faltam vagas nas instituições, sendo criados critérios de admissão que muitas vezes ferem o direito subjetivo disposto na legislação.

Em 2013, a obrigatoriedade foi reafirmada pela Lei n. 12.796 (Brasil, 2013a), que referendou a necessidade de matrícula na pré-escola para as crianças de 4 e 5 anos, ou seja, para uma parte da educação infantil, com prazo para implementação até o ano de 2016. Com relação à obrigatoriedade da educação infantil em outros países da América Latina, a despeito de algumas poucas diferenças, os objetivos e finalidades são bastante semelhantes. Assim como ocorre no Brasil, a pré-escola aproxima-se da universalização, enquanto a faixa etária que compreende crianças entre 0 e 3 anos de idade tem atendimento muito inferior à demanda da sociedade (Brasil, 2013b).

Se o ensino se tornou obrigatório a partir dos 4 ou 5 anos de idade, as experiências nos municípios brasileiros evidenciam que o atendimento destinado às crianças entre 0 e 3 anos de idade pode sofrer defasagem. O número de vagas ofertadas continua sendo insuficiente, uma vez que os recursos tendem a ser aplicados no segmento onde prevalece a obrigatoriedade.

A obrigatoriedade da frequência com cinco e com quatro anos direcionou a atenção prioritária dos sistemas de ensino para essas idades, visando à sua universalização, o que trouxe, como consequência, menos atenção e menos recursos para a educação do nascimento ou a partir de 45 dias até os 3 anos de idade (Brasil, 2013b, p. 119).

Segundo Moss (2011), o discurso globalizado em relação ao acesso e ao direito à educação infantil acontece com vistas ao ingresso da criança ao ensino fundamental, com o intuito de atingir padrões e comportamentos normativos. Desse modo, há um preparo da criança para que ela ingresse à nova etapa de ensino de forma que possa se adaptar mais facilmente. Nesse entendimento, corre-se o risco de focar naquilo que a criança virá a ser, negligenciando o que ela já é e reduzindo os encaminhamentos a ações preparatórias para os anos posteriores da escolarização.

A importância e o papel da família na educação e no cuidado da criança ficam evidentes nos diversos países, sendo enaltecida a necessidade de articulação com as instituições de ensino para que haja uma efetiva e contínua comunicação, participação e complementação dos processos pedagógicos (Brasil, 2013b).

Uma vez que a oferta e administração do ensino cabem aos municípios, e estes, por sua vez, têm geralmente lidado com problemas de ordem financeira, estrutural e 
profissional para atender ao disposto na lei, o direito e a obrigação de matrícula para as crianças de 4 e 5 anos de idade enfrentam desafios para se efetivar. Além disso, a obrigatoriedade traz uma série de questionamentos quanto a sua implementação que merecem ser considerados. De acordo com Lira et al. (2016, p. 89),

A legislação e as políticas implementadas acabam criando uma falsa impressão de ampliação do acesso que, mesmo quando acontece, de forma localizada, se dá em condições inadequadas para garantir o desenvolvimento e a aprendizagem das crianças pequenas. E mesmo que fosse em condições adequadas, ainda assim, poderíamos questionar o direito dos pais de não optar pela frequência escolar aos quatro anos de idade.

Desse modo, temos acompanhado que alguns municípios têm adotado como estratégia o encaminhamento das crianças que deveriam ser atendidas em Centros de Educação Infantil para turmas em escolas de ensino fundamental. Isso é permitido pela legislação, desde que haja condições e sejam respeitadas as especificidades das crianças pequenas, contudo, infelizmente, muitas instituições não dispõem de mobiliário, estrutura e espaços adequados. Essa condição pode comprometer o desenvolvimento integral da criança, sua livre expressão, seu direito de brincar e explorar espaços.

O que nos chama a atenção no município pesquisado também é a formação dos profissionais que trabalham com essas crianças na pré-escola. A maioria tem formação em cursos de licenciatura, não necessariamente em Pedagogia, mas é concursada para atuar no ensino fundamental. Este aspecto foi objeto de reflexão de Lira et al. (2016, p. 90):

Como as crianças frequentam instituições, que atendiam prioritariamente outros níveis de ensino, os professores que assumem tais turmas são profissionais concursados para atuar no ensino fundamental. Em geral, o que acontece é que as turmas ficam com os professores novos na escola, recém-admitidos ou transferidos, que 'não têm escolha' e precisam assumir, muitas vezes a contragosto, as turmas de educação infantil.

Além disso, as crianças que antes frequentavam jornada integral nos Centros de Educação Infantil passaram a ser atendidas em jornada parcial, cabendo às famílias encontrar meios de lidar com esse novo arranjo. Diante dos aspectos elencados decorrentes da implementação da obrigatoriedade, interessou-nos saber como as famílias têm interpretado esses encaminhamentos.

O primeiro contato que o ser humano tem com a sociedade, e com um dado grupo social, se dá por meio da família, haja vista que esta é a primeira instituição social na qual o indivíduo é inserido. A família, por sua vez, é incumbida da tarefa de educar, de maneira informal, ao mesmo tempo em que transmite ensinamentos e formas de comportamentos socialmente aceitos e construídos historicamente pelo homem, conhecimentos do senso comum, configurando o início da socialização do indivíduo.

A escola, como instituição em que o indivíduo é inserido já com pouca idade, é responsável pela transmissão e elaboração do conhecimento de forma sistemática. Sua finalidade, portanto, inclui proporcionar aos indivíduos a aquisição de saberes em áreas 
distintas do conhecimento e, especialmente nessa faixa etária, promover situações de interação e troca de experiências. Especificidades à parte, família e escola têm funções complementares no desenvolvimento do processo educativo, buscando melhor preparar o indivíduo para a vida em sociedade, o que exige uma relação de parceria.

Desse modo, é importante que a escola crie espaços que estejam abertos para a interação e participação da família, tornando-a consciente da importância de seu papel durante o processo educativo como um todo, e não somente em seus resultados, como a participação em reuniões para entrega de pareceres e boletins, por exemplo. Segundo Parolin (2007, p. 36), "A qualidade do relacionamento que a família e a escola construírem será determinante para o bom andamento do processo de aprender e de ensinar do estudante e o seu bem viver em ambas as instituições".

Deste modo, para que o processo de ensino-aprendizagem da criança seja positivo e significativo, a parceria entre escola e família deve ser constante e incentivada.

\section{As famílias diante da obrigatoriedade de matrícula para a pré-escola}

A partir do exposto, consideramos pertinente fazer uma coleta de dados junto aos pais responsáveis por crianças que frequentam a pré-escola a fim de reconhecer quais suas percepções acerca da determinação legal a partir dos encaminhamentos dados pela legislação e pelo município. Para tanto, lançamos mão de entrevistas semiestruturadas, que foram gravadas e transcritas, com os adultos responsáveis cujas crianças estavam matriculadas em duas turmas de pré-escola: uma situada no contexto de uma escola de ensino fundamental e outra em um Centro Municipal de Educação Infantil (CMEI) de um município de médio porte do interior do Paraná ${ }^{2}$. As conversas foram realizadas em pequenos grupos no ano de 2016, em dias em que os responsáveis foram às instituições para reuniões pedagógicas agendadas pelas professoras. Participaram das entrevistas 5 mães cujos filhos ou filhas estavam frequentando a pré-escola na escola e 7 mães cujas crianças frequentavam a pré-escola no CMEl. Cabe registrar que encontramos dificuldades em conversar com os responsáveis pelas crianças, que em sua maioria não manifestaram disponibilidade para tal.

As entrevistas seguiram um roteiro semiestruturado que buscou investigar desde compreensões sobre as finalidades e os objetivos da educação infantil, até as percepções acerca da obrigatoriedade de matrícula na pré-escola e os possíveis impactos dessa determinação legal e seus desdobramentos na vida das famílias. Em função das perguntas elaboradas e das respostas das participantes, os dados foram organizados em categorias, que representam os subtítulos que seguem e traduzem os aspectos

2 No ano de 2016, quando foram realizadas as entrevistas, o município contava com turmas de pré-escola tanto nos CMEls (em menor número), quanto no contexto das escolas de ensino fundamental. A partir de 2017, o panorama mudou, uma vez que todas as crianças de 4 e 5 anos de idade passaram a ser atendidas em turmas de pré-escola na escola. 


\section{A obrigatoriedade e o direito à educação}

Dando enfoque às determinações dispostas na Lei n. 12.796 (Brasil, 2013a), iniciamos a entrevista perguntando às mães se concordavam com a obrigatoriedade de matrícula e se consideravam que a entrada na pré-escola era importante para seus filhos naquela fase de suas vidas. A maioria das entrevistadas no CMEl seguiu a ideia exposta nas respostas abaixo:

É importante que as crianças entrem na escola mais cedo, porque a maioria dos pais e mães trabalham e precisam deixar as crianças em algum lugar. Além disso, as crianças têm o direito à aprendizagem na vida, e de forma mais rápida, vão tendo uma iniciação na vida escolar (FALA DE MÃE DE CRIANÇA DA PRÉ-ESCOLA NO CMEI).

Percebemos, por meio das falas, que para as mães não estão claros os objetivos da educação infantil explicitados na legislação e nos documentos oficiais. Prevalece o reconhecimento do caráter assistencialista dos atendimentos em vista de seu trabalho, sendo confundida a obrigatoriedade de matrícula na educação infantil com a entrada da criança na escola que alfabetiza. Sobre a dissociação entre cuidado e educação, Kishimoto (2001, p. 7-8) ressalva:

Muitos privilegiam o educar e o cuidar apenas na dimensão pedagógica. É necessário concebêlos em uma perspectiva mais ampla, de um desenvolvimento que se processa num plano, [...]. Desde o berçário, em todas as ações do cotidiano, é preciso integrar ações de cuidado e educação [...]

As mães responsáveis pelas crianças que frequentavam a turma de pré-escola na escola, com relação ao mesmo questionamento, também destacam a importância de a criança frequentar a instituição, sendo, contudo, verbalizado em primeiro lugar o papel de tal prática no desenvolvimento das crianças. A mudança de espaço - o fato da criança estar fora do CMEI - representa às mães que agora a função institucional é do ensino, não sendo mencionado o cuidado.

É importante para o desenvolvimento das crianças, inclusive se minha filha tivesse entrado antes na escola, seu desenvolvimento estaria bem mais adiantado (MÃE DE UMA CRIANÇA DA PRÉ-ESCOLA NA ESCOLA).

A pressa na aprendizagem é, muitas vezes, um desejo dos pais, mas de forma alguma o processo de ensino deve responder a esses anseios, mas sim apoiar-se nas diretrizes que norteiam as práticas, nesse caso da educação infantil. De modo geral, prevalece a ideia de que a educação infantil "só cuida", quando na verdade todas as ações diárias com as crianças envolvem educação quando bem planejadas pelos professores. Ao brincar, ao alimentar-se, nas relações que estabelecem com seus pares, com os adultos e com os objetos os pequenos reinterpretam as coisas e o mundo a sua volta, com impactos sobre o seu desenvolvimento. 
Para as mães, a educação infantil parece ter importância primeiramente pela necessidade que têm de um lugar para deixar os filhos enquanto trabalham, compreensão que precisa ser considerada e atendida, mas que não explicita as finalidades e os objetivos da educação infantil enquanto direito das crianças. Nesse sentido, foi possível reconhecer que não está claro que as instituições de educação infantil são projetadas, pensadas e planejadas para atender as crianças de 0 a 5 anos de idade como um direito garantido, condição que coloca a relevância de que sejam apresentadas e esclarecidas às famílias as intencionalidades e a proposta de trabalho dos estabelecimentos.

Após breve explanação da Lei n. 12.796 no que diz respeito à obrigatoriedade, refizemos a pergunta questionando às mães se concordavam ou discordavam com o disposto na legislação. Uma das mães respondeu:

Concordo, porque as crianças vão se desenvolvendo intelectualmente e pegando gosto pela escola desde pequenos. Além disso, vão se preparando para um futuro melhor, aprendendo a ler e a escrever mais cedo, além de aprender o convívio social, o que melhora o comportamento (MÃE DE UMA CRIANÇA DE PRÉ-ESCOLA DO CMEI).

A fala da mãe reflete uma compreensão de que quanto mais cedo a criança for para a escola mais aprenderá, ou seja, que mais anos de escolarização poderiam garantir melhor socialização e um maior sucesso profissional.

\section{A antecipação da alfabetização}

A preocupação com a aprendizagem evidenciada na fala das mães revelou também que esperam da educação infantil um trabalho voltado para a alfabetização, o ensino sistemático de letras e números.

Se no passado a criança brincava até entrar na escola aos 7 anos para ser alfabetizada, o esperado é que a criança hoje tivesse também o direito à brincadeira, tendo mudado apenas do espaço livre para o espaço especializado. Porém, se a idade de ingresso na escola adiantou, adiantou também a expectativa com a alfabetização. Existe hoje uma grande expectativa com a alfabetização precoce [...] (Albano, 2012, p. 55).

$\mathrm{Na}$ percepção das mães prevalece a ideia da educação infantil como preparação para os anos posteriores da escolarização, ou seja, quanto mais cedo a criança entrar na escola e aprender a ler e escrever melhor para ela. Segundo relatos das próprias mães, as práticas nas turmas de pré-escola têm correspondido a esse equivocado entendimento, focando em exercícios de escrita de letras e números em detrimento da brincadeira, que deveria ser o eixo do trabalho pedagógico na educação infantil. Não desconsideramos que tanto as escolas como os CMEls são espaços sociais, onde se aprende também a viver em sociedade, com contato inclusive com a linguagem escrita, por meio das ações desenvolvidas e das interações que ocorrem entre as crianças e os adultos que lá se encontram. Contudo, Craidy e Barbosa (2012, p. 35) nos fazem um importante alerta: 
Antecipar muitas vezes é perder tempo e não ganhar tempo. Modificações na educação básica brasileira, são, certamente, necessárias; porém, é preciso lembrar que as crianças, os professores e as famílias brasileiras exigem, e merecem, respeito.

Quando perguntamos às mães o que elas achavam que seus filhos iriam aprender na pré-escola, a grande maioria respondeu que eles seriam alfabetizados:

Acho que eles aprenderão a ler, a escrever, a compartilhar as coisas, a fazer novos amigos (MÃE DE UMA CRIANÇA DA PRÉ-ESCOLA DO CMEI).

Eu acho que eles vão aprender as cores, letras, alfabeto, números, vogais, lateralidade, sentidos (MÃE DE UMA CRIANÇA DA PRÉ-ESCOLA NA ESCOLA).

Frente a essas colocações reiteramos que, para as famílias, não está clara a função da educação infantil, equívoco que é reforçado pela insistência em práticas voltadas para a alfabetização no cotidiano do trabalho com as crianças. Não negamos que a criança de 4 e 5 anos pode alfabetizar-se, pois vivemos numa sociedade letrada, em que há signos e símbolos, letras e palavras nos mais variados lugares, contudo esse deve ser um processo disparado pelo interesse acerca da função social da escrita e não apressado pelas práticas na educação infantil.

Entendemos, sim, que para uma criança é importante saber que lhe querem bem, que é inteligente e capaz de aprender inúmeras coisas, cada uma ao seu tempo; como sujeito em desenvolvimento, precisa sentir-se segura, poder fantasiar em seu mundo especialmente mágico, brincando e sendo criança, no sentido mais profundo da palavra.

O objetivo da Educação Infantil, do ponto de vista do conhecimento e da aprendizagem, é o de favorecer experiências que permitam às crianças a apropriação e a imersão em sua sociedade, através das práticas sociais de sua cultura, das linguagens que essa cultura produz, e produziu, para construir, expressar e comunicar significados e sentidos.

É evidente que se torna imprescindível oferecer às crianças situações práticas e vivências que possam ser processadas e sistematizadas por um corpo que sente e pensa, desde o nascimento. Por esse motivo, é preciso escolher outras formas de priorizar, selecionar, classificar e organizar conhecimentos, mais próximos das experiências dinâmicas das crianças e não da visão fragmentada da especialização disciplinar, problematizada pela própria ciência (Brasil, 2009c, p. 47-48).

Dando prosseguimento em nossas entrevistas, indagamos às mães das crianças ainda sobre o que esperavam que seus filhos aprendessem aos 4 e 5 anos de idade e obtivemos as seguintes respostas, dentre outras:

Espero que aprenda a ler, a escrever e a fazer amigos (MÃE DE UMA CRIANÇA DA PRÉ-ESCOLA DO CMEI).

Que faça muitos amigos (MÃE DE UMA CRIANÇA DA PRÉ-ESCOLA DO CMEI).

Eu espero que ele reconheça o alfabeto, as letras, o próprio nome, os números, porque esperar 
que sejam alfabetizados é exigir demais deles (MÃE DE UMA CRIANÇA DA PRÉ-ESCOLA NA ESCOLA).

Espero que eles tenham noção sobre o alfabeto, saibam os números, saibam contar até 10 (MÃE DE UMA CRIANÇA DA PRÉ-ESCOLA NA ESCOLA).

Embora seja mencionado o fato das crianças fazerem amigos nessa etapa de ensino, novamente vemos explicitado o anseio pela aprendizagem das letras e números. Tal condição revela que, muitas vezes, falta aos responsáveis pelas instituições e professores apresentar aos pais a proposta de ensino, os objetivos de seu trabalho e como ele será desenvolvido. Pelo contrário, ao que parece, as instituições têm respondido com práticas escolarizantes contrariando o que dizem os documentos, a legislação e os pesquisadores da área da educação infantil.

Assim, para a criança interessa saber que será respeitada e entendida como um ser em constante desenvolvimento, fazendo parte de uma educação infantil com objetivos próprios e não aqueles atrelados às etapas posteriores da escolarização.

\section{A educação infantil como oportunidade de socialização das crianças}

Perguntamos também às mães o que seria mais importante para o desenvolvimento da criança nessa fase de sua vida, a convivência familiar ou com outras crianças da mesma idade. Nas respostas preponderou o entendimento de que tanto a família como a convivência das crianças nas instituições são importantes ao desenvolvimento infantil, à socialização e humanização:

Tanto a convivência familiar quanto a convivência com outras crianças são de extrema importância, mas a criança deve estabelecer uma convivência com as outras crianças sim (MÃE DE UMA CRIANÇA DA PRÉ-ESCOLA DO CMEI).

Eles precisam do contato com outras crianças para desenvolver-se bem no meio social (MÃE DE UMA CRIANÇA DA PRÉ-ESCOLA DO CMEI).

Na minha opinião, a criança não deve ser criada fechada, mas deve ter convivência com outras pessoas, outras crianças, outras raças e assim poder perceber que todo mundo é igual independentemente da cor (MÃE DE UMA CRIANÇA DA PRÉ-ESCOLA NA ESCOLA).

Desta maneira, foi possível perceber que as mães têm consciência da importância do meio social e cultural para o desenvolvimento das crianças, uma vez que é também na interação que ocorre entre as crianças que o desenvolvimento cognitivo, afetivo e social acontece. Nesses momentos, há troca de experiências, novas vivências, internalização de regras e comportamentos próprios da cultura de cada sociedade em determinada época.

Mais especificamente com relação à obrigatoriedade, perguntamos se, caso a matrícula na pré-escola não fosse obrigatória, elas matriculariam seus filhos. 
Sim, pois ele tem o direito de estudar e aprender as coisas (MÃE DE UMA CRIANÇA DA PRÉESCOLA DO CMEI).

Sim, inclusive porque desde bebê, meu filho já frequentava a educação infantil na creche (MÃE DE UMA CRIANÇA DA PRÉ-ESCOLA NA ESCOLA).

Sim, porque em casa às vezes eles não têm muito o que fazer, ficam "aprontando", ou ficam sozinhos, e na escola tem outras crianças. (MÃE DE UMA CRIANÇA DA PRÉ-ESCOLA NA ESCOLA).

Aqui, percebemos a manifestação do interesse pela educação infantil, pois é um direito da criança e promove a socialização. Fica ainda evidente a necessidade dessa etapa de ensino para as famílias trabalhadoras.

Quando perguntado às mães se sentiam segurança ao deixar seus filhos nas instituições, aos 4 e 5 anos, responderam:

Sim, pois acredito que esteja em mãos de pessoas competentes a cuidar e ensinar (MÃE DE UMA CRIANÇA DA PRÉ-ESCOLA DO CMEI).

Sim. Acredito que tem pessoas capacitadas para cuidar de nossos filhos, pois em casa, muitas vezes, não se tem limite e nem regras (MÃE DE UMA CRIANÇA DA PRÉ-ESCOLA DO CMEI).

Eu tenho insegurança em deixar meu filho, porque ele é "traquino", porque ele cai, se machuca (MÃE DE UMA CRIANÇA DA PRÉ-ESCOLA NA ESCOLA).

Tenho medo que meu filho se "misture" com os alunos maiores (MÃE DE UMA CRIANÇA DA PRÉ-ESCOLA NA ESCOLA).

Se observarmos as respostas, reconhece-se que para as mães das crianças que frequentam turmas de pré-escola no CMEI não há insegurança, sendo destacado o cuidado como uma ação esperada, embora não reconhecida como princípio educativo. Já para as responsáveis das crianças de turmas de pré-escola, na escola a questão da segurança aparece como uma preocupação, associada tanto ao comportamento pessoal como também ao fato de estarem em instituições que antes atendiam apenas a crianças maiores. Nesse sentido, corroboramos com o entendimento de Lira et al. (2016, p. 95) de que

[...] a extensão da obrigatoriedade do ensino deve vir acompanhada de financiamento público para que a educação infantil, seja oferecida em instituições com condições adequadas de estrutura e de corpo docente e com uma proposta pedagógica específica para a referida faixa etária.

Destarte, para que a educação infantil seja de qualidade, nos seus mais variados aspectos, há a necessidade de propostas adequadas, formação de professores e estruturas bem planejadas, condições que dependem sobremaneira de investimentos financeiros. 


\section{A obrigatoriedade e os impactos na dinâmica da vida familiar e da criança}

Prosseguimos com nossa entrevista questionando se a transferência da matrícula de seu filho da creche (no caso de crianças que eram matriculadas em creches) para a pré-escola causaria algum tipo de transtorno às famílias e às crianças e quais seriam:

Pode causar transtorno sim, pois é tudo diferente, rotina, regras, é uma nova adaptação, mas eles se acostumam (MÃE DE UMA CRIANÇA DA PRÉ-ESCOLA DO CMEI).

Trouxe transtorno, porque antes meu filho ficava o dia todo na creche, e agora como ele vem para o pré somente meio período, eu tenho que pagar uma pessoa para ficar com ele durante o período em que não tem aula, mas é só isso (MÃE DE UMA CRIANÇA DA PRÉ-ESCOLA NA ESCOLA).

As respostas indicaram que as mães manifestam preocupação com a rotina que provavelmente será diferente, mas vem à tona também a estratégia do município para atender as crianças da pré-escola em jornada parcial, de quatro horas diárias. Essa condição gera uma situação que exige adequação dos pais, que precisam buscar outras alternativas, uma vez que, em sua maioria, trabalham. Assim, a entrada obrigatória das crianças na escolarização formal interferiu na vida das famílias, pois exigiu uma reorganização da logística de apoio, porque se antes as crianças ficavam durante o dia todo na instituição, agora passaram a ser atendidas em meio período. Nesse sentido, outras pessoas foram acionadas para estar com os pequenos (avós, tios, babás), ou em alguns casos, como nos contaram as mães, elas precisaram deixar seus empregos para estar neste período com as crianças ou colocá-las em outras instituições privadas.

Perguntamos ainda se achavam que essa entrada "precoce" na escola iria interferir na educação dada aos filhos em casa e entenderam que não.

Eu acho que negativamente não vai interferir porque mesmo que meu filho aprenda outras coisas com outras crianças, eu corrijo ele em casa. Positivamente ajuda, porque melhora a convivência dele com outras pessoas e diminui o egoísmo porque aprende a dividir (MÃE DE UMA CRIANÇA DA PRÉ-ESCOLA NA ESCOLA).

Interfere positivamente, ficam mais amorosos com outras crianças, afetivos e menos egoístas. Deixam de lado o ciúme que têm inclusive em relação ao irmão mais velho (MÃE DE UMA CRIANÇA DA PRÉ-ESCOLA DO CMEI).

Fica clara nas falas a importância da parceria que deve ocorrer entre família e instituições de ensino no sentido de complementação das ações desenvolvidas com vistas ao desenvolvimento infantil.

Por fim, perguntamos se a matrícula na pré-escola era entendida por elas como uma obrigação ou como um direito: 
A matrícula é um direito das crianças, e a entrada na educação infantil ajuda muito no desenvolvimento das mesmas, no aprendizado de coisas importantes, no bom comportamento, na socialização, na ocupação do tempo delas com coisas que são e que serão importantes para o futuro delas (MÃE DE UMA CRIANÇA DA PRÉ-ESCOLA NA ESCOLA).

É um direito de toda criança que está na idade de ir para escola. (MÃE DE UMA CRIANÇA DA PRÉ-ESCOLA DO CMEI).

Como um direito das crianças e dever dos pais (MÃE DE UMA CRIANÇA DA PRÉ-ESCOLA DO CMEI).

Aqui, fica evidenciado que as entrevistadas, sem exceção, encaram a obrigatoriedade pela vertente do direito de seus filhos sem, contudo, questionar a imposição advinda da lei. Isso traz um dever para a família, de matrícula, e retira sua possibilidade de escolha, mas esses aspectos não são mencionados.

\section{Considerações finais}

Analisando o contexto de implementação da Lei n. 12.796 (Brasil, 2013a) e considerando as inúmeras questões envolvidas nesse processo, nosso objetivo foi o de compreender como as famílias estavam interpretando a obrigatoriedade de matrícula na pré-escola a partir dos desdobramentos práticos que as afetavam.

Constatamos que as famílias, na figura das mães, reconhecem a educação infantil como um direito, embora tenham revelado uma incompreensão quanto às suas finalidades, bem como ficaram evidentes algumas preocupações envoltas nessa ida das turmas de pré-escola para a escola. Apareceram questões ligadas à estrutura física que pode não ser suficientemente adequada e segura para as crianças pequenas e também as dificuldades para a família com a redução da jornada de atendimento. Contudo, a impressão recolhida foi de que, para as famílias, esses aspectos não são tomados como ônus, mas são consequências, aceitas, em vista da exigência legal e da garantia do direito à vaga.

Outro ponto que nos chamou atenção nas falas das entrevistadas é que, para as famílias cujas crianças ainda são atendidas em turmas de pré-escola nos CMEls, a ida para turmas na escola é entendida como matrícula no ensino fundamental, ou seja, não reconhecem a pré-escola como parte obrigatória da etapa da educação infantil. Tal compreensão se justifica, em nossa interpretação, dado o contexto de atendimento (o local onde serão atendidas - a escola), bem como as práticas escolarizantes desenvolvidas.

Inicialmente, dado nosso conhecimento de que o município reduzira a jornada de atendimento para meio período, colocando as crianças no contexto das instituições de ensino fundamental, dentre outros aspectos, tínhamos como hipótese que a implementação pela forma como vinha ocorrendo poderia estar trazendo grandes dificuldades para as famílias. Os resultados nos indicaram que, embora em algum momento as famílias mencionem alguns pontos negativos decorrentes dos 
encaminhamentos tomados pelo município, eles não são sentidos como relevantes ou preocupantes, prevalecendo um conformismo com a situação, provavelmente, dentre outras questões, decorrente das incompreensões acerca dos objetivos e das finalidades da educação infantil e de como deveriam estar organizadas as práticas e as instituições. Tal condição reforça ainda mais a necessidade de encontrar meios para esclarecer à população acerca de seus direitos, que incluem uma educação pública de qualidade, o que requer reconhecer a própria creche e pré-escola como espaço-tempo privilegiado para promover essas compreensões.

No que se refere ao tema central desse artigo, com foco na obrigatoriedade de matrícula para as crianças de 4 e 5 anos na pré-escola, colocadas as disposições legais e organizadas as estratégias de atendimento, a tarefa é descortinar as condições reais de efetivação da obrigatoriedade, analisando-as a partir dos diferentes atores nela envolvidos.

\section{Referências}

Albano, A. A. (2012). O espaço do desenho: a educação do educador. 15. Ed. São Paulo. Edições Loyola.

Brasil. (1996). Lei n. 9394 de 20 de dezembro de 1996. Estabelece as Diretrizes e Bases da Educação Nacional. Brasília, 1996. Recuperado em 20 de maio de 2013, de https://www.planalto.gov.br.

Brasil. (2006). Parâmetros básicos de infraestrutura para instituições de educação infantil. (2006). Brasília: DF: MEC. Recuperado em 17 de fevereiro de 2017, de http:// portal.mec.gov.br/seb/arquivos/pdf/Educinf/miolo_infraestr.pdf.

Brasil. (2012). Diretrizes Curriculares Nacionais para a Educação Infantil. (2009a). Brasília, Ministério da Educação. Recuperado em 29 de janeiro de 2012, de www.mec. gov.br.

Brasil. (2009). Emenda Constitucional n. 59, de 11 de novembro de 2009. (2009b). Acrescenta $\S 3^{\circ}$ ao art. 76 do Ato das Disposições Constitucionais Transitórias para reduzir, anualmente, a partir do exercício de 2009, o percentual da Desvinculação das Receitas da União incidente sobre os recursos destinados à manutenção e desenvolvimento do ensino de que trata o art. 212 da Constituição Federal, dá nova redação aos incisos I e VII do art. 208, de forma a prever a obrigatoriedade do ensino de quatro a dezessete anos e ampliar a abrangência dos programas suplementares para todas as etapas da educação básica, e dá nova redação ao $\S 4^{\circ}$ do art. 211 e ao $\S 3^{\circ}$ do art. 212 e ao caput do art. 214 , com a inserção neste dispositivo de inciso VI. Diário Oficial da União, Brasília, DF.

Projeto de cooperação técnica MEC e UFRGS para construção de orientações curriculares para a educação infantil. (2009c). Brasília, Ministério da Educação/Uni- 
versidade Federal do Rio Grande do Sul. Recuperado em 25 de maio de 2017, de http://portal.mec.gov.br/dmdocuments/relat_seb_praticas_cotidianas.pdf.

Brasil. (2013). Lei 12.796 de 04 de abril de 2013. (2013a). Altera a Lei no 9.394, de 20 de dezembro de 1996, que estabelece as diretrizes e bases da educação nacional, para dispor sobre a formação dos profissionais da educação e dar outras providências. Recuperado em 19 de maio de 2013, de https://www.planalto.gov.br/ccivil_03/_ ato2011-2014/2013/lei/l12796.htm.

Brasil. (2013). A educação infantil nos países do MERCOSUL: análise comparativa da legislação. (2013b). Ministério da Educação. Secretaria de Educação Básica. Brasília: MEC/SEB, $132 \mathrm{p}$.

Campos, M. M. (2010). A educação Infantil como direito. Insumos para o Debate 2. Emenda Constitucional n. ${ }^{\circ}$ 59/2009 e a educação infantil: impactos e perspectivas. São Paulo: Campanha Nacional pelo direito à educação. Recuperado em 3 de outubro de 2016, de http://www.mieib.org.br/admin/arquivos/biblioteca/insumos_para_o_debate_2.2011-07-01_23-45-21.pdf.

Constituição Federal de 1988. (1988). Brasília, DF: Senado Federal, 1988. Recuperado em 20 de maio de 2013, de https://www.planalto.gov.br.

Cury, C. R. J. (2008, maio). A educação básica como direito. Cadernos de Pesquisa, São Paulo, v. 38, n. 134, p. 293-303.

Craydi, C. M.; Barbosa, Maria C. S. (2012). Ingresso obrigatório no ensino fundamental aos 6 anos: falsa solução para um falso problema. In: Barbosa, Maria C. S. et al. A infância no ensino fundamental de 9 anos. Porto Alegre: Penso.

Freire, P. (1997). Professora sim, tia não. Cartas a quem ousa ensinar. São Paulo: Olho d'água.

Kishimoto, T. M. (2001). A LDB e as instituições de educação infantil: desafios e perspectivas. Rev. Paul. de Educ. Fís., São Paulo, supl. 4, p. 7-14.

Lira, A. C. M.; Drewinski, J. M. de A. \& Sapelli, M. L. S. (2016). Educação infantil para crianças de quatro e cinco anos: entre a obrigatoriedade, o direito e a imposição. Imagens da Educação, Maringá, v. 6, n. 2, p. 84-97.

Moss, P. (2011, abril). Qual o futuro da relação entre educação infantil e ensino obrigatório? Cadernos de Pesquisa, São Paulo, v. 41, n.142, p.142-159.

Oliveira, Z. de M. R de. (1994). Educação Infantil: muitos olhares. São Paulo. Cortez.

Parolin, I. C. H. (2007). Pais e Educadores: quem tem tempo de educar? Porto Alegre: Mediação. 


\section{Biografia}

\section{Aliandra Cristina Mesomo Lira}

Docente do Departamento de Pedagogia e do Programa de Pós-Graduação em Educação da Universidade Estadual do Centro-Oeste/UNICENTRO, Guarapuava/PR; Doutora em Educação pela Universidade de São Paulo/USP.

E-mail: aliandralira@gmail.com / ORCID: http://orcid.org/0000-0003-2945-464X

\section{Leandra Souza Machado}

Licenciada em Pedagogia docência e gestão educacional pela Universidade Estadual do Centro-Oeste - UNICENTRO. Tem experiência na área de Educação, com ênfase em Educação.

E-mail: liasouza0808@gmail.com 